\title{
SYNCHRONIZED NITROGEN RELEASE FROM POLYMER COATED NITROCHALK ENHANCES NITROGEN USE EFFICIENCY AND YIELD OF WHEAT
}

\author{
Muhammad Awais Khalid ${ }^{1, *}$, Muhammad Yaseen ${ }^{1}$, Muhammad Naveed ${ }^{1}$ and Rashid Ahmad $^{2}$ \\ ${ }^{1}$ Institute of Soil and Environmental Sciences, University of Agriculture, Faisalabad-38040, Pakistan; \\ ${ }^{2}$ Department of Agronomy, University of Agriculture, Faisalabad-38040, Pakistan. \\ "Corresponding author's e-mail:_mawais1410@gmail.com
}

\begin{abstract}
Efficiency of conventionally applied nitrogen $(\mathrm{N})$ fertilizers ranges from 35 to $45 \%$. Poor efficiency due to prompt release of excess nitrogen in the soil also threats environment. The nitrogen fertilizers performance can be enhanced by controlling the release of nitrogen through encapsulation with polymer and synchronizing the nitrogen release with plant up-take pattern. To test this hypothesis series of experiments were conducted. Nitro-chalk (calcium ammonium nitrate) as test $\mathrm{N}$ fertilizer was used for polymer coating. Laboratory and pot experiments were conducted to determine the effective polymer thickness coated on nitro-chalk, and results revealed that two layers of polymer performed the best as consistent release of $\mathrm{N}$ significantly increased growth and yield attributes of wheat. Similarly, coated nitro-chalk also corresponded well to the nitrogen requirements of wheat plants in field. Consequently, polymer coated treatments significantly improved wheat grain yield by 10 to $17 \%$ compared with uncoated fertilizer at the same nitrogen application rate. Reducing the rate of application of polymer coated nitro-chalk by $25 \%$ produced more grain yield as compared with the application of recommended rate of commercial nitro-chalk. Therefore, the results suggested efficient release of nitrogen from coated nitro-chalk increased production and nitrogen use efficiency. Furthermore, a 25\% less application of nitrogen as polymer coated nitro-chalk than recommended application rate of nitrogen can be an effective measure to save input cost as well as increase in grain yield.
\end{abstract}

Keywords: Wheat, nitro-chalk, polymer, nitrogen volatilization, grain yield

\section{INTRODUCTION}

Nitrogen has a significant role in yield production of wheat. The availability of nitrogen is the main factor that affect grain yield of wheat (Halitligil et al., 2000). Consequently, in developing countries bulky amount of nitrogen fertilizers are applied over the past 20 years to meet crops demand (Mueller et al., 2012; Huang et al., 2008). However, response of crop yield is much lower compared to increasing application rate of nitrogen (Cai et al., 2002). While excessive application of nitrogen fertilizers in field cause adverse effect on environment and soil through leaching and volatilization (Shang et al., 2014; Rochette et al., 2009). So, it is mandatory to optimize nitrogen inputs with wheat requirement and to reduce environmental pollution.

Nitrogen use efficiency (NUE) could be improved by synchronizing nitrogen release from applied fertilizer according to wheat requirement. Different strategies have been employed to improve efficiency and to reduce losses of nitrogen (Chen et al., 2012; Soon et al., 2011). Basic point is reducing the time span, that nitrogen spent in soil prior to crop uptake, could decrease the exposure of nitrogen to loss and increasing its efficiency (Grant et al., 2012).

Polymer coated fertilizers have been introduced to provide consistent nutrient supply for a longer period (Song et al.,
2005). As polymer thickness significantly affects release rate of nutrient (Suharti et al., 2016), so release rate of ammonium and nitrate can be controlled by thickness of the coating film (Perez-Garcia et al.,2007).

Polymer coated fertilizers are very expensive and its use is only limited to valuable ornamental plants. It is crucial to develop an economically viable and environment and userfriendly polymer coated nitrogen source which synchronizes nitrogen release with wheat demand. Effectiveness of polymer coating on nitrogen source (Nitro-chalk) was investigated in this study. Ideal combination which synched with wheat requirement was identified that fulfilled crop nitrogen demand. Series of laboratory, pot and field experiments were conducted to find out number of coating layers of polymer on fertilizer suitable for improving wheat growth and yield.

\section{MATERIALS AND METHODS}

Laboratory and pot study: Commercially available nitrochalk was coated with water soluble polymer (Carbonyl Polyacrylamide) in Soil Fertility and Plant Nutrition Lab, Institute of Soil and Environmental Sciences, University of Agriculture, Faisalabad. Coating thickness, of 1\% polymer strength, was maintained as (single, double and triple) on 
fertilizer for lab and pot trials. Coated fertilizers were allowed to dry under laboratory conditions at $25^{\circ} \mathrm{C}$ and stored in polyethylene bags till the application as described by Yaseen et al. (2017).

Bulk amount of soil used for the lab and pot trials was collected from the field at Research Area of Institute of Soil and Environmental Sciences, University of Agriculture, Faisalabad, Pakistan. Soil of the experimental site was sandy clay loam in texture with ECe $1.96 \mathrm{dS} \mathrm{m}^{-1}$ (Richards, 1954), pH 7.7 (Prasad et al., 2006), organic matter contents $0.64 \%$ (Walkey and Black, 1934), total N contents $0.04 \%$ (Jackson, 1962), Olsen P $6.2 \mathrm{mg} \mathrm{kg}^{-1}$ soil (Olsen et al., 1954) and extractable K $115 \mathrm{mg} \mathrm{kg}^{-1}$ soil (Hanways and Heidel, 1952). Disposable cups of $250 \mathrm{~cm}^{3}$ were used during lab study. Each cup was filled with $200 \mathrm{~g}$ soil. Saturation percentage of soil was determined to maintain required moisture content. Fertilizers with respective thickness i.e. uncoated, single, double and triple layers of coating (at the rate of $0.25 \mathrm{~g} \mathrm{~N} / 100$ $\mathrm{g}$ of soil) were applied in cups according to treatment plan and mixed in soil thoroughly. Cups were placed randomly in incubator (Sanyo; MIR 253) at temperature $25 \pm 2{ }^{\circ} \mathrm{C}$ after addition of water as per field capacity which was maintained by adding distilled water after every 24 hours. Total nitrogen was determined after different time interval 15, 30, 45 and 60 days by method (Keeney and Nelson, 1982). Two the best performing polymer thicknesses (double and triple layer) were selected for pot experiment.

Above described soil was filled in pots at the rate of $14 \mathrm{~kg}$ per pot with gentle packing. This experiment was comprised of four treatments i.e. $\mathrm{T}_{1}=$ Control (without any fertilizers), $\mathrm{T}_{2}$ $=\mathrm{PK}$ (phosphorus + potassium $)+$ uncoated nitrochalk, $\mathrm{T}_{3}=$ $\mathrm{PK}+$ double coated nitrochalk, $\mathrm{T}_{4}=\mathrm{PK}+$ triple coated nitrochalk. Treatment was planned according to completely randomized design with three replications. Recommended rates of fertilizers for wheat $\left(\mathrm{N}=120 \mathrm{~kg} \mathrm{ha}^{-1}, \mathrm{P}_{2} \mathrm{O}_{5}=90 \mathrm{~kg}\right.$ $\mathrm{ha}^{-1}$ and $\mathrm{K}_{2} \mathrm{O}=60 \mathrm{~kg} \mathrm{ha}^{-1}$ ) were added as coated and uncoated nitrochalk $(26 \% \mathrm{~N})$, single super phosphate $\left(18 \% \mathrm{P}_{2} \mathrm{O}_{5}\right)$ and sulphate of potash $\left(50 \% \mathrm{~K}_{2} \mathrm{O}\right)$. Five seeds of wheat $\mathrm{cv}$. Faisalabad-2008 per pot were sown at $1 \mathrm{~cm}$ depth and only two seedlings were maintained after germination at two leaf stage. Pots were irrigated with canal water to maintain approximate field capacity level. At harvest, grain and straw yield was recorded for each pot. At booting stage, physiological parameters like photosynthetic rate and water use efficiency were determined using CIRAS-3 (PP System, Amesbury, MA, USA) and for chlorophyll content, portable meter SPAD-501 was used. Nitrogen and potassium contents (Chapman and Pratt, 1961) and phosphorus (Olsen et al., 1954) were also determined.

Field study: The field experimental plan for wheat crop was comprised of five treatments i.e. $\mathrm{T}_{1}=$ Control (without any fertilizers), $\mathrm{T}_{2}=\mathrm{PK}$ (phosphorus + potassium) $+\mathrm{N}$ from uncoated nitro-chalk at $100 \%$ recommended rate, $\mathrm{T}_{3}=\mathrm{PK}+$ $\mathrm{N}$ from polymer coated nitro-chalk at $100 \%$ recommended rate, $\mathrm{T}_{4}=\mathrm{PK}+\mathrm{N}$ from polymer coated nitro-chalk at $75 \%$ recommended rate, $\mathrm{T}_{5}=\mathrm{PK}+\mathrm{N}$ from polymer coated nitrochalk at $50 \%$ recommended rate. The experimental design used was randomized complete block design with three replications and analyzed statistically (Steel et al., 1997). Recommended doses of NPK and fertilizer sources were same as used in pot study. Soil textural class and wheat variety (Faisalabad-2008) was similar as lab and pot trials. Crop was irrigated five times with canal water. At harvesting 1 square meter area was randomly selected in each plot for measuring growth and yield attributes 20 days before harvesting and average values were computed. Grain and straw yields were recorded for each plot. The total productivity of crops was worked out while biological yield was calculated by formula given below.

$$
\begin{aligned}
\text { Biological Yield } & =\text { Total biomass of plants in plot (grain } \\
& + \text { straw yield) }
\end{aligned}
$$

For physiological and chemical parameters determination, same procedure was followed as in pot experiment. Nitrogen uptake was calculated by the formula:

$$
\text { Nitrogen Uptake }=\frac{\text { oven dried weight of plant } \times N(\%)}{100}
$$

Total $\mathrm{N}$ uptake $=\mathrm{N}$ uptake in grain $+\mathrm{N}$ uptake in straw Agronomic recovery efficiency (ARE)

$\operatorname{ARE}(\%)=\frac{\text { uptake by fertilized plant }- \text { uptake by unfertilized plant } \times 100}{\text { amount of fertilizer applied }}$

\section{RESULTS}

Laboratory experiment: Interaction of different coating thicknesses of polymer on nitro-chalk and days were statistically analyzed and found significant effect. Uncoated nitro-chalk was found less efficient in slowing down nitrogen release as maximum nitrogen contents were released within first 15 days compared to different number of coatings of polymer on fertilizer grain (Table 1). While the nitrogen release from coated fertilizers was slow and consistent because coatings of polymer hold the nutrient, and slowed down rate of its release. Among days, maximum nitrogen release was observed in single coated nitro-chalk fertilizer after 15 days interval as this coating thickness was comparatively less firm than other number of coating layers on fertilizer. After 30 days of incubation, coated fertilizers showed almost constant nitrogen release from one time interval to another up to certain limit except single layer of coating. Maximum nitrogen content was observed in double layer coated fertilizer. Triple coated nitro-chalk fertilizer also showed significant increase in nitrogen content compared to previous determination, but release was slow compared to double layer. After 45 days of incubation period there was increased nitrogen concentration in soil treated with triple layer coated nitro-chalk followed by double layer coated fertilizer. From single and double layer of polymer coated fertilizers the nitrogen release was decreased. After 60 days of incubation single layer coated fertilizer showed least 
Nitrogen use efficiency of polymer coated nitrochalk

Table 1. Release pattern of nitrogen $\left(\mu \mathrm{g} \mathrm{g}^{-1}\right)$ in soil treated with polymer coated nitro chalk.

\begin{tabular}{lccccc}
\hline Treatment & \multicolumn{3}{c}{ Incubation intervals (days) } & \multirow{2}{*}{ Mean } \\
\cline { 2 - 4 } & $\mathbf{1 5}$ & $\mathbf{3 0}$ & $\mathbf{4 5}$ & $\mathbf{6 0}$ & \\
\hline Uncoated Nitro chalk (Control) & $1692.6 \mathrm{a}$ & $731.2 \mathrm{e}$ & $115.0 \mathrm{~h}$ & $45.0 \mathrm{i}$ & $645.9 \mathrm{D}$ \\
Single coated Nitro chalk & $1360.5 \mathrm{~b}$ & $1021.9 \mathrm{c}$ & $526.0 \mathrm{f}$ & $229.0 \mathrm{~g}$ & $784.3 \mathrm{C}$ \\
Double coated Nitro chalk & $1287.3 \mathrm{~b}$ & $1018.0 \mathrm{c}$ & $816.8 \mathrm{de}$ & $457.1 \mathrm{f}$ & $894.7 \mathrm{~A}$ \\
Triple coated Nitro chalk & $741.9 \mathrm{e}$ & $862.5 \mathrm{~d}$ & $965.6 \mathrm{c}$ & $743.0 \mathrm{e}$ & $828.2 \mathrm{~B}$ \\
Mean & $1039.6 \mathrm{~A}$ & $740.1 \mathrm{~B}$ & $486.4 \mathrm{C}$ & $295.8 \mathrm{D}$ & \\
\hline
\end{tabular}

Values sharing same letter(s) do not differ at $\mathrm{p}=0.05$ according to HSD test. HSD values (critical values for comparison): Mean for days $=31.08$, Mean for polymer coating layers $=37.03$, Interactions $($ days $\times$ coating layers $)=98.24$

Table 2. Effect of polymer coated nitro chalk on growth and yield components of wheat under greenhouse (pot) experiment.

\begin{tabular}{|c|c|c|c|c|c|c|c|c|}
\hline \multirow[t]{2}{*}{ Treatment } & \multirow[t]{2}{*}{$\begin{array}{l}\text { Plant height } \\
\quad(\mathrm{cm})\end{array}$} & \multirow[t]{2}{*}{$\begin{array}{c}\text { Grain } \\
\text { weight }\left(\mathrm{g} \mathrm{pot}^{-1}\right)\end{array}$} & \multirow[t]{2}{*}{$\begin{array}{l}\text { Photosynthetic } \\
\text { rate }\end{array}$} & \multirow[t]{2}{*}{$\begin{array}{l}\text { Chlorophyll } \\
\text { content }\end{array}$} & \multirow[t]{2}{*}{$\begin{array}{c}\text { Water use } \\
\text { efficiency }(\%)\end{array}$} & \multicolumn{3}{|c|}{$\begin{array}{c}\text { Nutrient composition in } \\
\text { wheat grain }(\%)\end{array}$} \\
\hline & & & & & & $\mathbf{N}$ & $\mathbf{P}$ & $\mathbf{K}$ \\
\hline Control & $42.3 d$ & $5.89 \mathrm{c}$ & $7.1 \mathrm{~d}$ & $33 c$ & $2.59 \mathrm{~d}$ & $0.40 \mathrm{~d}$ & $0.09 \mathrm{~d}$ & $1.08 \mathrm{c}$ \\
\hline U-Nitro chalk & $55.3 \mathrm{c}$ & $6.47 \mathrm{c}$ & $9.3 \mathrm{c}$ & 41 & $3.01 \mathrm{c}$ & $1.37 \mathrm{c}$ & $0.31 \mathrm{c}$ & $1.66 \mathrm{c}$ \\
\hline D-Nitro chalk & $70.7 \mathrm{a}$ & $10.41 \mathrm{a}$ & $13.8 \mathrm{a}$ & $45 \mathrm{a}$ & $4.12 \mathrm{a}$ & $2.26 \mathrm{a}$ & $0.47 \mathrm{a}$ & $2.39 a$ \\
\hline T-Nitro chalk & $66.0 \mathrm{~b}$ & $8.46 \mathrm{~b}$ & $11.1 \mathrm{~b}$ & $41 \mathrm{~b}$ & $3.67 \mathrm{~d}$ & $1.96 \mathrm{~b}$ & $0.39 b$ & $2.27 \mathrm{~b}$ \\
\hline
\end{tabular}

Control $=$ without any fertilizer, U-Nitro chalk = Uncoated nitro chalk, D-Nitro chalk $=$ Double layer of polymer coated nitro chalk, T-

Nitro chalk $=$ Triple layer of polymer coated nitro chalk. Values sharing same letter do not differ at $p=0.05$ according to HSD test

Table 3. Effect of coated nitro chalk on growth and yield components of wheat under field experiment.

\begin{tabular}{lccccc}
\hline $\begin{array}{l}\text { Fertilizer application } \\
\text { rate }\left(\mathbf{k g ~ h a}^{-1}\right)\end{array}$ & $\begin{array}{c}\text { Plant height } \\
(\mathbf{c m})\end{array}$ & $\begin{array}{c}\text { No. of fertile } \\
\text { tillers }\left(\mathbf{m}^{-2}\right)\end{array}$ & $\begin{array}{c}\text { 1000 grain } \\
\text { weight }(\mathbf{g})\end{array}$ & \multicolumn{2}{c}{ Yield parameter $\left(\mathbf{k g ~ h a}^{-\mathbf{1}}\right)$} \\
\hline Control & $95.5 \mathrm{c}$ & $260.7 \mathrm{~b}$ & $25.03 \mathrm{c}$ & $2460.0 \mathrm{~d}$ & Grain yield \\
U-Nitro chalk $(100 \%)$ & $99.0 \mathrm{bc}$ & $342.7 \mathrm{ab}$ & $32.40 \mathrm{~b}$ & $4446.7 \mathrm{bc}$ & $9200 \mathrm{bc}$ \\
C-Nitro chalk $(100 \%)$ & $102.3 \mathrm{a}$ & $469.3 \mathrm{a}$ & $38.27 \mathrm{a}$ & $5213.3 \mathrm{a}$ & $12007 \mathrm{a}$ \\
C-Nitro chalk $(75 \%)$ & $101.1 \mathrm{ab}$ & $385.3 \mathrm{ab}$ & $35.47 \mathrm{a}$ & $4880.0 \mathrm{~b}$ & $10507 \mathrm{ab}$ \\
C-Nitro chalk $(50 \%)$ & $99.5 \mathrm{bc}$ & $347.7 \mathrm{ab}$ & $29.43 \mathrm{~b}$ & $4526.7 \mathrm{c}$ & $8947 \mathrm{bc}$ \\
\hline
\end{tabular}

Control $=$ without any fertilizer, U-Nitro chalk $(100 \%)=$ Uncoated nitro chalk at recommended rate, C-Nitro chalk $(100 \%)=$ Polymer coated Nitro chalk at recommended rate, C-Nitro chalk $(75 \%)=$ Polymer coated Nitro chalk at $75 \%$ of recommended rate, C-Nitro chalk $(50 \%)=$ Polymer coated Nitro chalk at $50 \%$ of recommended rate. Values sharing same letter(s) do not differ at $p=0.05$ according to HSD test

nitrogen release among the coated fertilizers treatments but it was still significantly higher than uncoated fertilizer (Table 1). In case of three layers of polymer on fertilizer, nitrogen concentration in soil was also significantly higher from the previous incubation period. Moreover, nitrogen concentration in soil was also more than that of double layer coated nitro-chalk, because of the presence of three layers of polymer.

Pot experiment: This experiment was conducted to screen the best performing polymer layer on fertilizer regarding nitrogen release to fulfill plant requirement. Table 2 indicated that double layer polymer coated nitro-chalk gave significant results over triple coated and uncoated nitrogenous fertilizer (Table 2). Double layered polymer coated increased number of fertile tillers, grain weight and photosynthetic rate 36,61 and $48 \%$, respectively, over uncoated fertilizer application.

\section{Field experiment}

Wheat growth and yield parameters: Polymer coated nitrochalk showed significant results over commercial uncoated nitro-chalk. Plant height and number of fertile tillers increased by $3.3 \%$ and $37 \%$ in plots treated with polymer coated nitrochalk than uncoated nitro-chalk fertilizer. There was $18 \%$ increase in 1000 grain weight with application of polymer coated nitro-chalk equal to recommended rate over recommended rate of uncoated nitro-chalk. Grain yield $(\mathrm{kg}$ $\mathrm{ha}^{-1}$ ) in the treatment of recommended rate of polymer coated nitro-chalk was statistically higher than all other treatments and it was $17 \%$ higher compared to uncoated fertilizer treatment. Moreover, application of polymer coated nitrochalk equal to $75 \%$ of recommended rate of nitro-chalk brought $10 \%$ improvement in grain yield $\left(\mathrm{kg} \mathrm{ha}^{-1}\right)$ compared to uncoated nitro-chalk (Table 3). Furthermore, biological yield $\left(\mathrm{kg} \mathrm{ha}^{-1}\right)$ was also improved in response to different rates of polymer coated fertilizer as compared to control as well as 
uncoated nitro-chalk fertilizer application. Maximum increase in biological yield $\left(\mathrm{kg} \mathrm{ha}^{-1}\right)$ was recorded in the treatment receiving recommended rate of polymer coated nitro-chalk, and it was $30 \%$ more as compare to uncoated nitro-chalk fertilizer application (Table 3).

Physiological parameters: Maximum chlorophyll contents were observed in plants treated with recommended rate of polymer coated nitro-chalk over uncoated nitro-chalk i.e. 3\% (Fig. 1). In the same way, a significant improvement in photosynthetic rate was recorded with the application of polymer coated nitro-chalk over control and uncoated treatments. There was, $9 \%$ and $2 \%$ increase in photosynthetic rate, with the application of $100 \%$ and $75 \%$ recommended rate of polymer coated nitro-chalk over uncoated fertilizer. With increase in photosynthetic rate water use efficiency was also increased $19 \%$ with the application of polymer coated fertilizer at $100 \%$ rate of recommendation compared to control (Fig. 1).

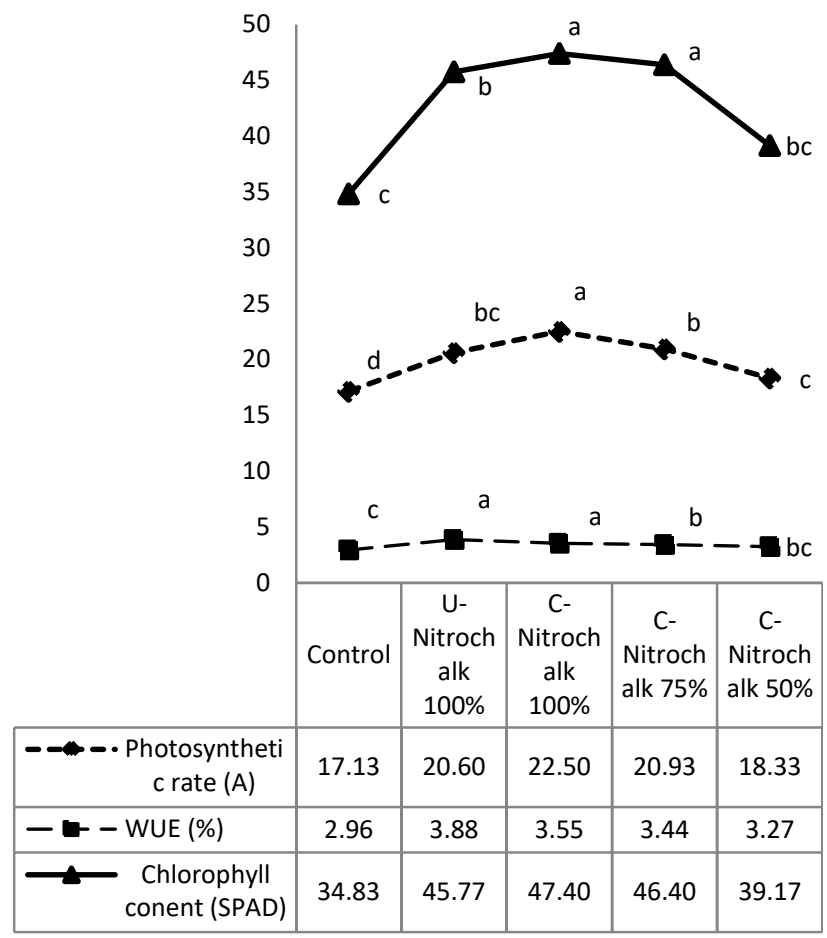

Control $=$ without any fertilizer, U- Nitro chalk $100 \%=$ Uncoated nitro chalk at recommended rate, $\mathrm{C}$-Nitro chalk $100 \%=$ Polymer coated Nitro chalk at recommended rate, C-Nitro chalk $75 \%=$ Polymer coated Nitro chalk at $75 \%$ of recommended rate, C-Nitro chalk $50 \%=$ Polymer coated Nitro chalk at $50 \%$ of recommended rate. Values sharing same letter(s) do not differ at $\mathrm{p}=0.05$ according to HSD test

Figure 1.Effect of polymer coated nitro chalk on physiological parameters of wheat.

Nutrient concentration in wheat straw and grain and total $n$ uptake: Figure 2 shows the N, P and K concentrations in grain of wheat. Polymer coated nitro-chalk had direct influence on $\mathrm{N}$ concentration in grain and it was significant; however, $\mathrm{P}$ and $\mathrm{K}$ concentrations were also indirectly influenced. Concentrations of $\mathrm{N}, \mathrm{P}$ and $\mathrm{K}$ in wheat grain were maximum with the application of polymer coated nitro-chalk particularly when applied at $100 \%$ rate of recommendation i.e. 34,16 and $33 \%$, respectively over uncoated. Application of $75 \%$ of recommended rate of polymer coated nitro-chalk showed statistically at par results of N, P and K concentration in grain with recommended rate of uncoated nitro-chalk (Fig. 2). Data on total $\mathrm{N}$ uptake by wheat is given in Figure 3. Total $\mathrm{N}$ uptake was influenced significantly by various rates of nitro-chalk coated with polymer. Maximum increase in $\mathrm{N}$ uptake was observed in the treatment receiving recommended rate of polymer coated nitro-chalk i.e. $17 \%$ over conventional uncoated nitro-chalk fertilizer application.

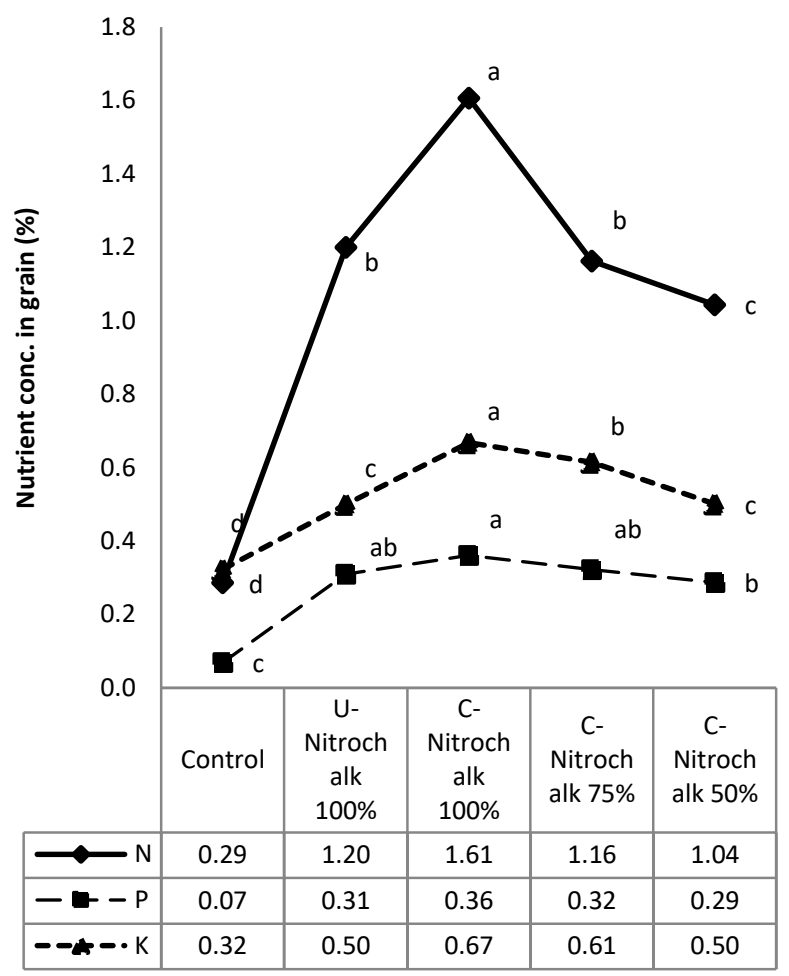

Control $=$ without any fertilizer, U- Nitro chalk $100 \%=$ Uncoated nitro chalk at recommended rate, C-Nitro chalk $100 \%=$ Polymer coated Nitro chalk at recommended rate, C-Nitro chalk $75 \%=$ Polymer coated Nitro chalk at $75 \%$ of recommended rate, C-Nitro chalk $50 \%=$ Polymer coated Nitro chalk at $50 \%$ of recommended rate. Values sharing same letter(s) do not differ at $\mathrm{p}=0.05$ according to HSD test

Figure 2. Effect of polymer coated nitro chalk on $\mathbf{N}, P$ and $K$ concentrations (\%) in wheat grain.

Recovery efficiency: Effect of polymer coated nitro-chalk on nitrogen recovery efficiency is reflected from the data given in Figure 3. Maximum recovery efficiency was observed in polymer coated nitro-chalk at $50 \%$ rate of recommendation 
i.e. $62 \%$ increased over uncoated fertilizer application (Fig. 3) because from limited $\mathrm{N}$ available, plant utilize maximum of it.

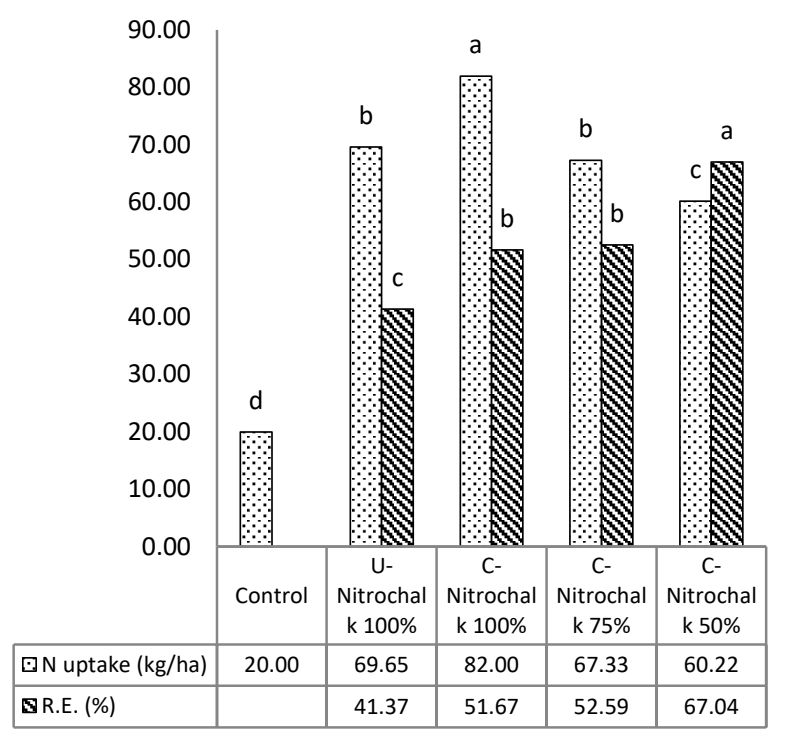

Control $=$ without any fertilizer, U- Nitro chalk $100 \%=$ Uncoated nitro chalk at recommended rate, C-Nitro chalk $100 \%=$ Polymer coated Nitro chalk at recommended rate, C-Nitro chalk $75 \%=$ Polymer coated Nitro chalk at $75 \%$ of recommended rate, C-Nitro chalk $50 \%=$ Polymer coated Nitro chalk at $50 \%$ of recommended rate. Values sharing same letter do not differ at $\mathrm{p}=0.05$ according to HSD test

Figure 3. Effect of polymer coated nitro chalk on $\mathrm{N}$ uptake and recovery efficiency in wheat crop.

\section{DISCUSSION}

Most of the conventional nitrogenous fertilizers are hygroscopic in nature (Obreza and Rouse, 2006), so highly soluble in water and immediately release maximum content of nitrogen after wetting. In contrast to this, plant nitrogen requirement is low at early growth stages, so little is taken up by plant where as remaining bulk amount of available nitrogen is left free and subjected to loss. For wheat, current nitrogen use efficiency (NUE) is not more than $50 \%$. Volatilization loses are more than $35 \%$ from surface application of nitrogenous fertilizer on alkaline and calcareous soil. Rapid release of $\mathrm{N}$ can be controlled by coating of polymer on nitro-chalk that provides physical barrier around fertilizer granule and slowed down the release of nitrogen (Timilsena et al., 2015).

The release rate of ammonium and nitrate can be controlled by thickness of the coating film (Perez-Garcia et al., 2007). By altering the thickness of the coating, the rate of nitrogen diffusion can be reduced. Finding the best coating thickness is critical for determination of nutrient release rate (Timilsena et al., 2015). By knowing the crop growth period and stages, an appropriate coating thickness can be used to match crop nitrogen demand (Fujinuma et al., 2009; Ellison et al., 2013).
Results of current experiments revealed that two numbers of coatings gave maximum control on nitrogen content released from nitro-chalk in soil, followed by three numbers of coatings.

Polymer coating on nitro-chalk can reduce nitrogen losses, but increase use efficiency only by appropriate coating thickness specific to crop (Chalk et al., 2015). From pot study, it is evident that two number of coatings of polymer on nitrochalk slowed the release of nitrogen in such a manner that the release pattern could closely match with the requirement of wheat plants. So, this competent treatment was also investigated with application of nitrogen fertilizer at reduced rates. Reduced application rates of controlled release nitrogen had positive effect on grain and straw yield of wheat (Yang et al., 2011).

Results of field study indicated that application of polymer coated nitro-chalk fertilizer significantly increased number of fertile tillers, biological yield, grain yield and nitrogen recovery efficiency compared to uncoated, might be due to slow release of nitrogen from coated fertilizer that synchronized well with plant nitrogen requirements (Xu et al., 2005). The polymer coated nitro-chalk significantly improved growth and yield of wheat under field conditions (Beres et al., 2010; Liang et al., 2012). Application of polymer coated nitro-chalk significantly increased the number of fertile tillers of wheat because of better nitrogen supply to the plants ( $\mathrm{Li}$ et $a l ., 2013)$. Increased number of fertile tillers of wheat plant had a good relationship with the grain yield of wheat. As there was more number of spikes as well as grains, therefore grain weight in the treatment of polymer coated nitro-chalk was higher than that of treatment of conventional way of application of this fertilizer and its control treatment. Maximum grain weight in the treatment of polymer coated nitro-chalk might be as a result of consistent supply of nitrogen at anthesis and grain filling growth stages (Li et al., 2013). It is also evident from increased chlorophyll content and photosynthetic rate of wheat plant due to application of recommended rate of polymer coated nitro-chalk. This treatment ensured normal regular supply of adequate nitrogen for wheat according to crop requirements.

The increased plant growth as a result of tillers, chlorophyll content, photosynthetic rate ultimately promoted the outcome i.e. grain yield. Consequences of all these are also depicted in the form of higher $\mathrm{N}$ recovery efficiency and lower $\mathrm{N}$ losses in the treatment of polymer coated fertilizer (Xu et al., 2013). Results of this experiment are evident that consistent nitrogen release from polymer coated nitro-chalk resulted in an improvement of nitrogen use efficiency (Tarlok and Rowsell, 2011) and reduction in nutrient losses (Emilsson et al., 2007). Nitrogen recovery efficiency and nitrogen uptake are major indicators of nitrogen use efficiency in the field studies (Peng et al., 2010; Weih et al., 2010; Zhang et al., 2008). 
Conclusion: All plants require nitrogen to complete their life cycles. Without adequate supply of nitrogen, plants produce less chlorophyll and proteins, which results in decreased growth and increased susceptibility to pests and diseases. Heavy applications of nitrogen based fertilizer are often applied to ensure high crop yields and to compensate for losses due to nitrogen escape from the soil. The process of applying fertilizers is often inefficient, thus leading towards a waste of natural resources and money. This practice often results in nitrogen loss as a pollutant to the environment through ammonia volatilization, nitrate leaching, and byproducts of denitrification, such as nitrous oxide. Therefore, the economic benefits of better efficiency, reduced environmental pollution and future damage can be achieved using polymer coated nitro-chalk.

Acknowledgement: The research work in this manuscript is a part of the project funded by Higher Education Commission (HEC), Pakistan. The authors are highly thankful to HEC.

\section{REFERENCES}

Beres, B.L., K.N. Harker, G.W. Clayton, E. Bremer, J.T.O. Donovan, R.E. Blackshaw and A.M. Smith. 2010. Influence of $\mathrm{N}$ fertilization method on weed growth, grain yield and grain protein concentration in no-till winter wheat. Can. J. Plant Sci. 90:637-644.

Cai, G.X., D.L. Chen, H. Ding, A. Pacholski, X.H. Fan and Z.L. Zhu. 2002. Nitrogen losses from fertilizers applied to maize, wheat and rice in the North China Plain. Nutr. Cycling Agroecosyst. 63:187-195.

Chalk, P.M., E.T. Craswell, J.C. Polidoro and D. Chen. 2015. Fate and efficiency of $15 \mathrm{~N}$ labeled slow and controlled release fertilizers. Nutr. Cycl. Agroecosyst. 102:167-178.

Chapman, H.D. and P.F. Pratt. 1961. Method of analysis for soils, plants and waters. Div. Agric Univ. California, USA. pp.150-179.

Chen, C., K. Neill, M. Burgess and A. Bekkerman. 2012. Agronomic benefit and economic potential of introducing fall-seeded pea and lentil into conventional wheat-based crop rotations. Agron. J. 104:215.

Ellison, E., A. Blaylock, C. Sanchez, and R. Smith. 2013. Exploring controlled release nitrogen fertilizers for vegetable and melon crop production in California and Arizona. Proc. West. Nutr. Manage. Conf. 10:17-22.

Emilsson, T., J.C. Berndtsson, J.E. Mattsson and K. Rolf. 2007. Effect of using conventional and controlled release fertilizer on nutrient runoff from various vegetated roof systems. Ecol. Eng. 29:260-271.

Fujinuma, R., N.J. Balster, and J.M. Norman. 2009. An improved model of nitrogen release for surface applied controlled release fertilizer. Soil Sci. Soc. Am. J. 73:2043-2050.
Grant, C., R. Wu, F. Selles, K. Harker, G. Clayton, S. Bittman, B. Zebarth and N. Lupwayi. 2012. Crop yield and nitrogen concentration with controlled release urea and split applications of nitrogen as compared to non-coated urea applied at seeding. Field Crops Res. 127:170-180.

Halitligil, M.B., A. Akin, N. Bilgin, Y. Deniz, K. Ogretir, B. Altmel, and Y. Isik. 2000. Effect of nitrogen fertilization on yield and nitrogen and water use efficiencies of winter wheat (durum and bread) varieties grown under conditions found in Central Anatolia. Biol. Fertil. Soils 31: $175-182$.

Hanway, J.J. and H. Heidel. 1952. Soil analysis methods as used in Iowa State College Soil Testing Laboratory, Bulletin 57. Iowa State College of Agriculture, USA: 131.

Huang, J.L., F. He, K.H. Cui, R.J. Buresh, B. Xu, W.H. Gong and S.B. Peng. 2008. Determination of optimal nitrogen rate for rice varieties sing a chlorophyll meter. Field Crops Res. 105:70-80.

Jackson, M.L. 1962. Chemical Composition of Soil. In: F.E. Bear (ed.), Chemistry of Soil. Van Nostrand Reinhold Co. New York, USA. pp.71-144.

Keeney, D.R. and D.W. Nelson. 1982. Nitrogen-inorganic forms. In: Methods of Soil Analysis, Part 2, A.L. pp. 643698.

Li, G., J. Yang, L. Yan and Y. Shi. 2013. The effects of controlled release fertilizer and conventional complex fertilizer on the dry matter accumulation and the yield in winter wheat. Res. J. Appl. Sci. Engineer. Technol. 5:2724-2728.

Liang, M.F., F.P. Song, Y. Gao and P. Zou. 2012. Effects of sulphur and polymer-coated controlled release urea fertilizers on wheat yield and quality and fertilizer nitrogen use efficiency. Chin. J. Appl. Ecol. 23:67-72.

Mueller, N.D., J.S. Gerber, M. Johnston, D.K. Ray, N. Ramankutty and J.A. Foley. 2012. Closing yield gaps through nutrient and water management. Nature 490:254-257.

Obreza, T.A. and R.E. Rouse. 2006. Long-term response of Hamlin orange trees to controlled-release nitrogen fertilizer. HortScience 41:423-426.

Olsen, S.R., C.V. Cole, F.S. Watanabe and L.A. Dean. 1954. Estimation of available phosphorus in soils by extraction with sodium bicarbonate. Circular No. 939, USDA. US Government Printing Office, Washington, DC.

Peng, S.B, R.J. Buresh, J.L. Huang, X.H. Zhong, Y.B. Zou, J.C. Yang, G.H. Wang, Y.Y. Liu, R.F. Hu, Q.Y. Tang, K.H. Cui and F.S. Zhang. 2010. Improving nitrogen fertilization in rice by site specific $\mathrm{N}$ management: A review. Agron. Sustain. Dev. 30:649-656.

Pérez-García, S., M. Fernández-Pérez, M. VillafrancaSánchez, E. González-Pradas and F. Flores-Céspedes. 2007. Controlled release of ammonium nitrate from 
ethylcellulose coated formulations. Ind. Eng. Chem. Res. 46:3304-3311.

Prasad, R., Y.S. Shivay, D. Kumar and S.N. Sharma. 2006. Learning by doing exercises in soil fertility (A practical manual for soil fertility). Division of Agronomy, Indian Agricultural Research Institute, New Dehli, Indi. 68.

Richards, L.A. 1954. Diagnosis and improvement of saline and alkali soil. USDA Agri. Handbook 60. Washington, D.C.

Rochette, P., D.A. Angers, M.H. Cantigny, J.D. MacDonald, N. Bissonnette and N. Betrand. 2009. Ammonia volatilization following surface application of urea to tilled and no-till soils: A laboratory comparison. Soil Till. Res. 103:310-315.

Shang, Q.Y., C.M. Gao, X.X. Yang, P.P. Wu, N. Ling, Q.R. Shen and S.W. Guo. 2014. Ammonia volatilization in Chinese double rice-cropping systems: A 3-year field measurement in long-term fertilizer experiments. Biol. Fert. Soils 50:715-725.

Song, F.P., M. Zhang, Y.X. Shi and Y.Y. Hu. 2005. Releasing characteristics of controlled release nitrogen fertilizer and its effects on rice yield. Acta Pedologica Sinica 42:619-627.

Soon, Y.K., S.S. Malhi, R.L. Lemke, N.Z. Lupwayi and C.A. Grant. 2011. Effect of polymer-coated urea and tillage on the dynamics of available $\mathrm{N}$ and nitrous oxide emission from Gray Luvisols. Nutr. Cycl. Agroecosys. 90:267279.

Steel, R.G.D., J.H. Torrie and D.A. Dickey. 1997. Principles and Procedures of Statistics: A biometrical approach, $2^{\text {nd }}$ Ed. McGraw Hill Inc., New York, USA.

Suharti, N., S. Sulaiman, Febriyenti, E. Zaini, M. Suardi, E.S. Ben and A. Djamaan. 2016. Effect of bioblend polystyrene/polycaprolactone and polystyrene/starch utilization toward coating thickness and release of active substance from urea granule. Der. Pharma. Chemica. 8:83-87.
Tarlok, S.S.C. and J. Rowsell. 2011. Comparative performance of urea and polymer coated urea (ESN) in timothy, and winter and spring wheat at Thunder Bay and New Liskeard. Northwest Link. pp.8-9.

Timilsena, Y.P., R. Adhikari, P. Casey, T. Muster, H. Gill and B. Adhikari. 2015. Enhanced efficiency fertilisers: a review of formulation and nutrient release patterns. J. Sci. Food Agr. 95:1131-1142.

Walkey, A.J. and I.A. Black. 1934. A critical examination of a rapid method for determining organic carbon in soils: Effect of variations in digestion conditions and of inorganic soil constituents. Soil Sci. 37:29-38.

Weih, M., L. Asplund and G. Bergkvist. 2010. Assessment of nutrient use in annual and perennial crops: A functional concept for analyzing nitrogen use efficiency. Plant Soil 339:513-520.

Xu, M., D. Li, J. Li, D. Qin, Y. Hosen and H. Shen. 2013. Polyolefin-coated urea decreases ammonia volatilization in a double rice system of southern china. Agron. J. 105:277-284.

Xu, M.G., X.F. Sun, C.M. Zou, D.Z. Qin, K.Y. Yagi and Y.K. Hosen. 2005. Effects and rational application of controlled-release nitrogen fertilizer in paddy field of southern China. Plant Nutr. Fert. Sci. 11:487-493.

Yang, Y.C., M. Zhang, L. Zheng, D.D. Cheng, M. Liu and Y.Q. Geng. 2011. Controlled release urea improved nitrogen use efficiency, yield, and quality of wheat. Agron. J. 103:479-485.

Yaseen, M., M.Z. Aziz, A. Manzoor, Y. Hameed, S. Noor, M.A. Khalid and M. Naveed. 2017. Promoting growth, yield and phosphorus use efficiency of crops in maizewheat cropping system by using polymer coated diammonium phosphate. Comm. Soil Sci. Plant Anal. 48:646-655.

Zhang, F.S., J.Q. Wang, W.F. Zhang, Z.L. Cui, W.Q. Ma, X.P. Chen and R.F. Jiang. 2008. Nutrient use efficiencies of major cereal crops in China and measures for improvement. Acta Pedol. Sin. 45:915-924. 